\title{
Warning Signs of Eating Disorders among Adolescent Girls in Visakhapatnam City
}

\author{
Dr. Krishnaveni Avvaru ${ }^{1} \&$ Dr. Sunita Sreegiri ${ }^{2}$ \\ 1. Professor, ${ }^{2}$. Associate Professor, \\ ${ }^{1,2}$ Dept of Community Medicine, Andhra medical College, Visakhapatnam.
}

\begin{abstract}
:
Research question: What are the warning signs of common eating disorders among adolescent girls and is it affecting their nutritional status? Methodology : A cross sectional study designed to 1) to assess the warning signs of eating disorders 2) to assess its effect on nutritional status and 3) to have an insight about actual weight as compared to perceived weight among adolescent girls studying in High school, junior college (+2/ intermediate courses) in Visakhapatnam City. A sample of 150 was considered for the study. Information on study variables was collected using a pretested questionnaire. Data was analyzed using MS Excel. Results: More than half had at least one of the warning signs of eating disorders; $64 \%$ skipped meals at various frequencies in a week, $43.33 \%$ were avoiding high fat diet and $62 \%$ were getting averted by former favorite food stuffs. Nearly one tenth of girls lost $5 \mathrm{kgs}$ of weight in short span of time and $40 \%$ had fear of weight gain. Mood variation/ irritability was experienced by $56 \%$. Menstrual irregularities were seen in $25 \%$. Conclusion: Warning signs of eating disorders were reported high among our adolescents suggesting a need for increase in awareness on key nutritional issues. Early detection of such behaviors and counseling will help bringing in behavioral change.
\end{abstract}

Key words: adolescent girls, BMI, behavioral signs, eating disorders, warning signs.

\section{Introduction}

Eating disorders are becoming increasingly prevalent among adolescents. These are mental illnesses, reflected through harmful disturbances in eating behaviors, typically in an effort to control body shape or weight (1). At risk groups include females between 12-20 yrs, sports persons, dancers, member of family with eating disorder etc. There is a spectrum of eating disorders that can be categorized into anorexia nervosa (AN) and bulimia nervosa (BN) and eating disorder not otherwise specified (ED-NOS)'. Younger age group are more likely to present with anorexia nervosa, while the older adolescent can present with either AN or BN (2). Key factor of treatment is in recognizing the warning signs and offering early intervention in cases of incipient eating disorders or problem with dieting behavior. Warning signs of suspected eating disorders include extreme dieting or disordered eating habits, skipping meals, avoid fatty diet or favorite food stuff, purging / induced vomiting, irregular menses, < BMI, weight loss or failure to reach expected gains(3). Hence an attempt has been made to assess the warning signs of eating disorders among teenage girls.

\section{Methodology}

A cross-sectional study was conducted among 150 teenage girls studying in high school, junior colleges ( +2 / intermediate courses) in Visakhapatnam city. The objectives were to 1) to assess the warning signs of eating disorders 2) to assess its effect on nutritional status and 3) to have an insight about actual weight as compared to perceived weight.

Participants were interviewed and information on variables such as Age, BMI, frequency of consumption of snacks, frequency of skipping meals and other behavioral sings were collected using a pretested questionnaire. Data was analyzed using Microsoft Excel Data sheet and expressed in the form of tables. Informed consent from all the subjects and permission from Head of the concerned institutions were taken.

\section{Results}

The total number of girls interviewed were 150 . The age of the study subjects ranged between 13 to 17 yrs. More than half of study population had at least one of the warning signs of eating disorders as shown in table 1 . 
Table no1: Distribution of girls according to the various warning signs observed

\begin{tabular}{|l|l|l|}
\hline Warning signs & Yes (\%) & No (\%) \\
\hline Self induced vomiting & 2 & 98 \\
\hline Percentage of girls avoiding high fat diet & 43.33 & 56.66 \\
\hline Percentage of girls getting aversion by former favorite food stuff & 38 \\
\hline lost 5 kg weight in short span of time & 62 & 90.7 \\
\hline Fear of weight gain/obesity & 9.3 & 60 \\
\hline Frequently seeing their image in mirror & 40 & 43 \\
\hline Frequently weighing themselves & 57 & 61 \\
\hline Wearing baggy clothes to cover weight loss & 39 & 94.66 \\
\hline Having dry skin & 5.33 & 69.33 \\
\hline Caries in teeth & 30.66 & 83.33 \\
\hline Menstrual cycles irregular & 16.66 & 74.66 \\
\hline Occasionally having excessive food & 25.33 & 61 \\
\hline Becoming moody or irritable & 39 & 44 \\
\hline
\end{tabular}

In our study, nearly half (43.33\%) stated that they avoid high fat diet and $62 \%$ were getting averted by former favorite food stuffs. Nearly one tenth of girls lost $5 \mathrm{kgs}$ of weight in short span of time and $40 \%$ had fear of weight gain. Mood variation/ irritability was experienced by $56 \%$. Menstrual irregularities were seen in $25 \%$ of the study population.

Table no 2: Distribution of study population as per BMI.

\begin{tabular}{|l|l|}
\hline BMI & $\mathbf{N}(\mathbf{\%})$ \\
\hline$<\mathbf{1 8 . 5}$ & $39(26 \%)$ \\
\hline $\mathbf{1 8 . 5}-\mathbf{2 2 . 9}$ & $64(42.66 \%)$ \\
\hline$>\mathbf{2 2 . 9}$ & $47(31.33 \%)$ \\
\hline
\end{tabular}

The table no 2 shows $42.66 \%$ of the girls were having BMI within normal range, $26 \%$ had BMI less than 18.5.

Table no 3 Distribution of study population according to actual vs. perceived body size

\begin{tabular}{|l|l|l|}
\hline $\begin{array}{l}\text { Body size } \\
\text { (BMI) }\end{array}$ & Actual & perceived \\
\hline Thin (<18.5) & $39(26 \%)$ & $55(36.66 \%)$ \\
\hline Normal (18.5-22.9) & $64(42.66 \%)$ & $57(38 \%)$ \\
\hline Overweight/obesity (>22.9) & $47(31.33 \%)$ & $38(25.3 \%)$ \\
\hline
\end{tabular}

Study participants in all the categories of BMI perceived their body size differently from actual body weight. As shown in table no 3 on observation $26 \%$ of girls were thin (having BMI $<18.5$ ) but $36.7 \%$ perceived themselves as thin.

Table no 4: Distribution of study population as per BMI and frequency of skipping meals in a week.

\begin{tabular}{|l|l|l|l|l|l|}
\hline BMI & $\mathbf{0}$ & $\mathbf{1}$ & $\mathbf{2}$ & $\mathbf{3}$ & $>\mathbf{3}$ \\
\hline$<\mathbf{1 8 . 5}$ & 9 & 4 & 6 & 8 & 12 \\
\hline $\mathbf{1 8 . 5}$ to 22.9 & 22 & 9 & 16 & 11 & 6 \\
\hline$>\mathbf{2 2 . 9}$ & 27 & 6 & 7 & 6 & 1 \\
\hline Total & $58(36 \%)$ & $19(16 \%)$ & $29(20 \%)$ & $25(15 \%)$ & $19(13 \%)$ \\
\hline
\end{tabular}

Various practices adopted to lose weight include skipping meals, heavy exercise, induced vomiting etc. In this study, 92 girls (64\%) stated that they skip meals at various frequencies in a week, among which 44 (47\%) skip 3 or more times a week. On further analysis it was found that those who skipped meals 3 or more times in a week had significantly less BMI as compared to the rest $(\mathrm{p}<0.05 . \mathrm{z}=8.25)$

It was also observed in this study that $18.66 \%$ of the girls undertook heavy exercise ( $>1 \mathrm{hr}), 3 \%$ adopted the practice of induced vomiting 


\section{Discussion}

Eating disorders are becoming more prevalent among adolescents. Conditions like Anorexia Nervosa have onset in early adolescence and by the time they reach late adolescence the impact is huge in the form of nutritional deficiency, reduced BMI or even psychiatric manifestations

The behavioral signs of eating disorders include, restricted eating such as skipping meals, avoid fatty diet, favorite food stuff, chronic purging, reduced BMI and protein energy malnutrition which was highly reported among our study participants. Nearly $2 / 3$ rd girls skipped meals at various frequencies in a week which in turn had significant impact on their BMI. As the frequency of skipping meals was increasing the BMI was decreasing. Menstrual irregularities were reported among $25 \%$ in our study. These findings were in concurrence with study by Pinhas et al (4). Such weight loss behaviors among teenage girls were also reported by a survey done by Boyce et al (5) in Canada.

More than half of our study population had at least one of the warning signs of eating disorders similar to findings from Project EAT where more than half of the girls were engaged in unhealthy weight control behaviors(6). In our study, one of the warning signs observed among girls attempting to lose weight is the difference in actual BMI and perceived BMI. Manifestation of such behavioral signs was also reported by Boyce et al (7).

\section{Conclusion}

Warning signs of eating disorders were reported high among our adolescents which suggests there is a need for increase in awareness regarding key nutritional issues that affect their overall health. Early detection and screening of teens with such behaviors should be undertaken by school authorities and parents with help of family physicians for counseling and behavioral change.

[1]. Encyclopedia of adolescence 2011, Pages 151-159

\section{References}

[2]. Gonzalez A, Kohn MR, Clarke SD. Eating disorders in adolescents. Aust Fam Physician. 2007 Aug ; 36(8):614-9.

[3]. Assessment of eating disorders tool kit-assessment and treatment planning - www.health.nsw.gov.au

[4]. Leora Pinhas, Anne Morris, Ross D. Crosby, Debra K. Katzman, Incidence and Age-Specific Presentation of Restrictive Eating Disorders in Children - A Canadian Paediatric Surveillance Program Study : Arch Pediatr Adolesc Med. 2011;165(10):895-899.

[5]. Boyce, W. F. Young people in Canada: their health and well-being. Ottawa, Ontario: Health Canada. 2004.

[6]. Project EAT - Epidemiology and community health research: www.sphresearch.umn.edu/epi/project eat.

[7]. Boyce W. F., King, M. A. \& Roche, J. Healthy Living and Healthy Weight. In Healthy Settings for Young People in Canada. 2008 